Thorax, 1978, 33, 769-772

\title{
Solitary rheumatoid nodule of the pleura and rheumatoid pleural effusion
}

\author{
A TSERKEZOGLOU, S METAKIDIS, H PAPASTAMATIOU-TSIMARA, \\ AND M ZOITOPOULOS \\ From the Department of Thoracic Surgery, Athens Chest Hospital, Athens, Greece
}

Tserkezoglou, A, Metakidis, S, Papastamatiou-Tsimara, H, and Zoitopoulos, M (1978), Thorax, 33, 769-772. Solitary rheumatoid nodule of the pleura and rheumatoid pleural effusion.

Pleuropulmonary rheumatoid nodules are rare. We report a case of solitary rheumatoid nodule of the pleura with cavitation and coexisting pleural effusion in a young woman.

Pulmonary and pleural lesions in rheumatoid arthritis have been known for many years. Solitary rheumatoid nodules of the lungs and the pleura are very rare, however (Martel et al, 1968; Schneider and Ehrlich, 1972). We describe a case of solitary rheumatoid nodule of the pleura with cavitation and rheumatoid pleural effusion in a young woman. No similar case has been reported.

\section{Case report}

A 20-year-old woman was admitted to a medical department of the Athens Chest Hospital complaining of chest pain, paroxysmal cough, and high temperature $\left(39^{\circ} \mathrm{C}\right)$. The patient had a history of recurrent episodes of pain and swelling of both knees. Her chest radiograph showed a right pleural effusion. At thoracentesis $1400 \mathrm{ml}$ of exudative fluid was removed. Its protein content was $53 \%$, it contained no measurable glucose, and the lactate dehydrogenase was 1860 units. Its white cells were lymphocytes $90 \%$ and neutrophils $10 \%$. Results of cytological and bacteriological examinations were negative. Haemoglobin, white cell count, blood urea, glucose, total protein, and serum bilirubin were within normal limits. The sedimentation rate was $119 \mathrm{~mm}$ per hour, the ASTO titre 50 units. and the Latex fixation test result was positive. The tuberculin test result was negative, and sputum cultures did not yield any acidfast bacilli.

The patient was given isoniazide $500 \mathrm{mg}$, ethambutol $450 \mathrm{mg}$, streptomycin $1 \mathrm{~g}$, and prednisone $25 \mathrm{mg}$ daily. The clinical manifestations subsided within a week. The chest radiograph after thoracentesis showed an egg-shaped lesion of the pleura in the right hemithorax, opposite the lower lobe and in the mid-axillary line.

Four months later she was admitted to our department because the pleural lesion was suspected to be a proliferating tumour. The chest radiograph was unchanged (fig 1).

Because of doubt about the diagnosis a thoracotomy was performed, and we found an eggshaped mass, $3 \mathrm{~cm} \times 6.5 \mathrm{~cm}$, located on the parietal pleura opposite the seventh rib. The lesion, which was not adherent to the right lung, was resected. The right lung and the rest of the pleura were normal. Histological examination of the excised mass showed a typical rheumatoid nodule with cavitation. There was a central necrobiotic zone with proliferating histiocytes, many of which had epithelial-like characteristics, an intermediate zone of inflammatory tissue with some giant multinucleate cells, and a peripheral zone of dense collagen fibres (figs 2 and 3 ).

The patient left the hospital 15 days later in good health.

\section{Discussion}

The pulmonary and pleural lesions in rheumatoid arthritis have been known for over a century. However, the histological evidence of the existence of such lesions, based on necropsy material, was provided only 30 years ago (Ellman and Ball, 1948). Pleuropulmonary lesions in rheumatoid arthritis are more common in men, while rheumatoid arthritis is almost three times more common in women (Ramirez and Campbell, 1966; Martel et al, 1968; Panettiere et al, 1968; Beumer and Van Belle, 1972). 


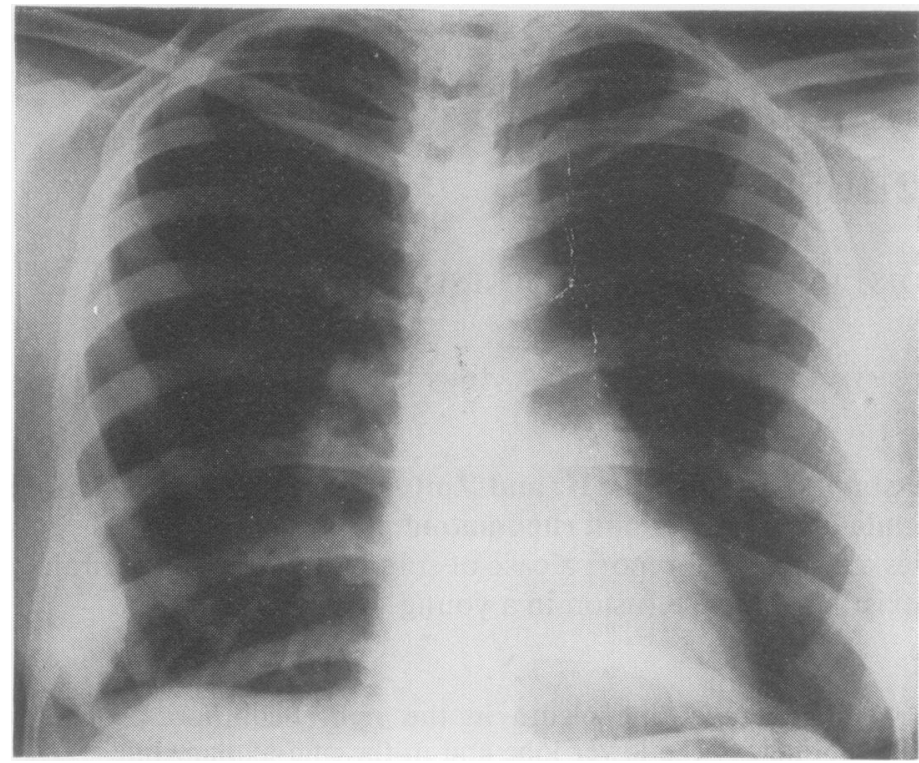

Fig 1 Chest radiograph showing a pleural mass in right hemithorax and $a \underset{\omega}{\omega}$ small pleural effusion.

The pathological manifestations of rheumatoid disease in the lungs and pleura are rheumatoid pleural effusion (Ellman et al, 1954; Martel et al, 1968), diffuse pulmonary fibrosis (Doctor and Snider, 1962; Martel et al, 1968), and multiple or solitary rheumatoid nodules (Robertson and Brinkman, 1961; Martel et al, 1968; Panettiere et $a l, 1968)$. The pleural effusion can be minimal or moderate in amount, asymptomatic, and often transient, but sometimes persistent. A characteristic feature is the low concentration of glucose in the pleural fluid (Martel et al, 1968; Schneider and Ehrlich, 1972). Rheumatoid chronic interstitial pneumonitis with varying degrees of fibrosis occurs quite often in rheumatoid arthritis, but it rarely coexists with pleuropulmonary rheumatoid nodules (Doctor and Snider, 1962; Martel et al, 1968; Beumer and Van Belle, 1972).

The rheumatoid nodules of the lung and the pleura are discrete, round, and occasionally slightly lobulated. They are usually multiple, and rarely solitary, lesions of variable diameter, ranging from several $\mathrm{mm}$ to $7 \mathrm{~cm}$. Cavitation of these nodules is rare (Ramirez and Campbell, 1966; Martel et al, 1968; Panettiere et al, 1968), but it was also seen in our case.

A biopsy should be performed to confirm the diagnosis (Panettiere et al, 1968; Beumer and Van Belle, 1972). Histologically these nodules consist of a central zone of fibrinoid degeneration or necrosis, an intermediate zone of proliferating cellular elements, and a peripheral zone of inflam- mation (Panettiere et al, 1968; Schneider and Ehrlich, 1972).

Clinical manifestations due to rheumatoid lesions of different systems can coexist with the $\varrho$ pleuropulmonary lesions in rheumatoid arthritis $\overrightarrow{\vec{O}}$ (Panettiere et al, 1968). A characteristic pathog- 3 nomonic finding in pleuropulmonary rheumatoid $\mathcal{F}$ lesions is a positive latex fixation test (Panettiere et al, 1968; Schneider and Ehrlich, 1972).

In cases of rheumatoid arthritis with pulmonaryo or pleural lesions steroid treatment may be $\tilde{x}$ effective (Beumer and Van Belle, 1972).

\section{References}

Beumer, H M, and Van Belle, C J (1972). Pulmonary nodules in rheumatoid arthritis. Respiration, 29, 을 $556-564$.

Doctor, L, and Snider, G L (1962). Diffuse interstitial $N^{\circ}$ pulmonary fibrosis associated with arthritis. $N$ American Review of Respiratory Disease, 85, 413422.

Ellman, P, and Ball, R E (1948). "Rheumatoid disease" with joint and pulmonary manifestations.0 British Medical Journal, 2, 816-820.

Ellman, P, Cudkowicz, L, and Ellwood, J S (1954). $\stackrel{\mathscr{\rho}}{?}$ Widespread serous membrane involvement by 0 rheumatoid nodules. Journal of Clinical Pathology, $\overrightarrow{\vec{D}}$ 239-244.

Martel, W, Abell, M R, Mikkelsen, W M, and $\stackrel{\oplus}{\Phi}$ Whitehouse, W M (1968). Pulmonary and pleuralo lesions in rheumatoid disease. Radiology, 90, 641-2 653. 

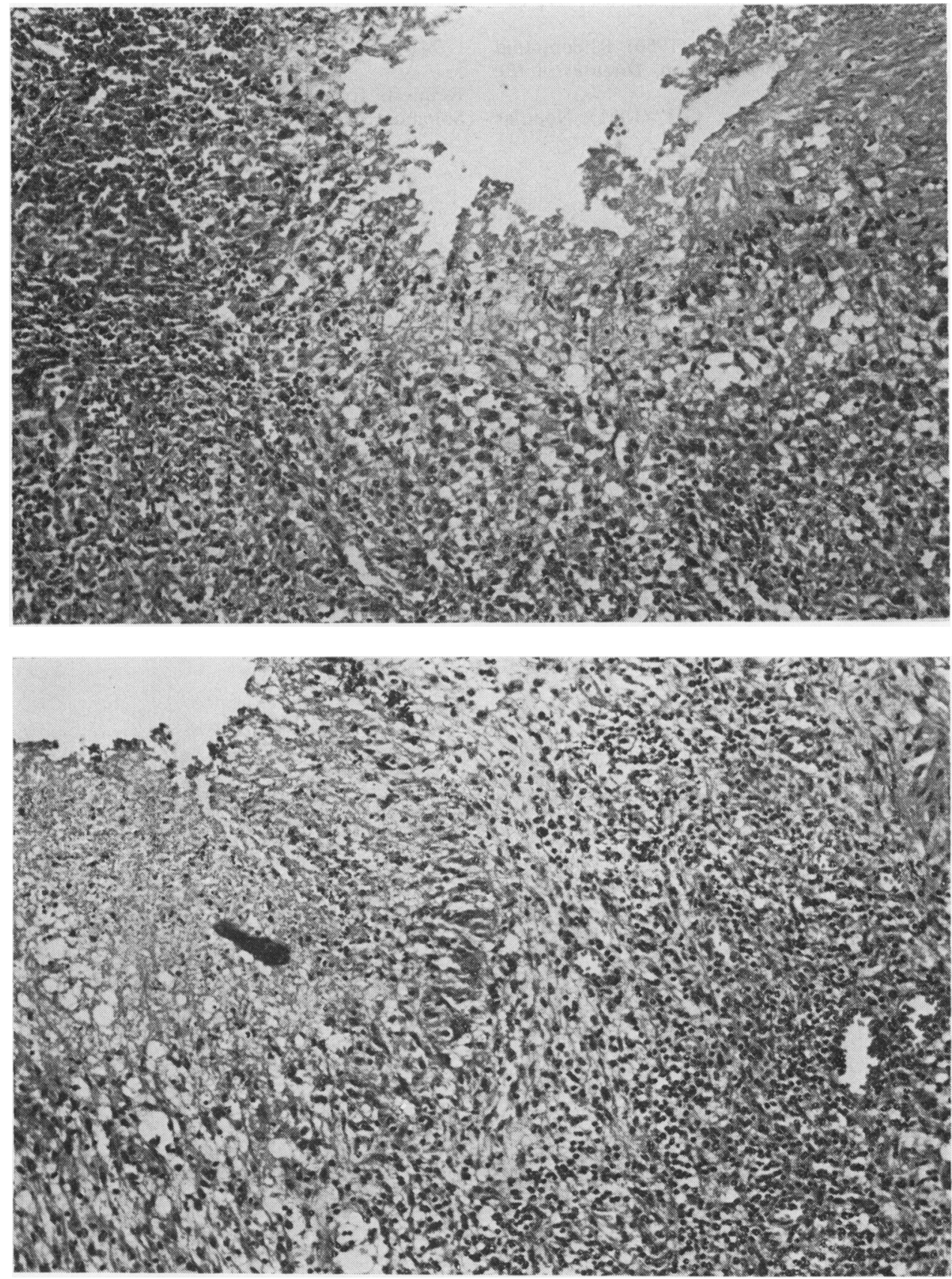

Figs 2 and 3 Microscopical pictures of lesion. Necrobiotic areas, partially of fibrinoid type, epithelioid histiocytes, and vascular inflammatory tissue, are well distinguished (Haematoxylin and eosin $\times 100$ ). 
Panettiere, F, Chandler, B F, and Libcke, J H (1968). Pulmonary cavitation in rheumatoid disease. American Review of Respiratory Disease, 97, 8995.

Ramirez-R, J, and Campbell, G D (1966). Rheumatoid disease of the lung with cavitation. Diseases of the Chest, 50, 544-547.

Robertson, J L, and Brinkman, G L (1961). Nodular rheumatoid lung disease. American Journal of Medicine, 31, 483-487.

Schneider, P J, and Ehrlich, G E (1972). Pulmonary lesions in rheumatoid arthritis. Chest, 62, $\mathrm{Nr} 6, \stackrel{\varnothing}{\varrho}$ 747-749.

Requests for reprints to: Dr Alice Tserkezoglou, $57 \vec{\circ}$

Solomou Street, Athens 102. 